\title{
MEMBERIKAN KENYAMANAN KONSUMEN SAAT DUDUK DI KABIN PENUMPANG PADA MOBIL TOYOTA RUSH 2009 DENGAN FITUR FOOT STAND JUGA SEBAGAI PELENGKAP DARI FITUR WHIPLASH INJURY LESSENING (WIL) CONCEPT SEAT
}

\author{
Agit Sakti Nur Kholis \\ Pendidikan Teknik Otomotif, Fakultas Teknik, Universitas Negeri Yogyakarta \\ Email: agitsakti.2019@student.uny.ac.id
}

\begin{abstract}
There are several cars with SUV type designs from the manufacturer with only 4 passenger seats with luggage, for example, one of them is the Toyota Rush 2009 and there are also those that have been designed for 7 passengers, such as the Isuzu MU-X and Daihatsu Terios. In this case it was found that several owners of SUVs with only 4 passengers, one of which was the Toyota Rush. Where the owner forced to modify the Toyota Rush from 4 passengers to 7 passengers. However, the increase in the number of seats can cause inconvenience for vehicle passengers in the rear row. Therefore, this article aims to design a foot stand on the Toyota Rush which is modified into 7 seats so that it can improve passenger comfort. The design process is carried out through the construction analysis, design, and simulation stages. The results show that the addition of a foot stand can increase comfort for passengers who sit in the back row because it has wider and more loose leg room.
\end{abstract}

Keywords: Consumer, foot stand, ergonomic, Comfort, Whiplash Injury Lessening (WIL) Concept Seat.

\begin{abstract}
Abstrak
Ada beberapa mobil dengan type SUV dengan disain dari pabrikan dengan hanya terdapat 4 kursi penumpang dengan bagasi contoh salah satunya yaitu Toyota Rush 2009 dan ada terdapat pula memang telah didisain untuk 7 penumpang yakni seperti Isuzu MU-X dan Daihatsu Terios. Pada kasus ini mendapati bahwa beberapa pemilik kendaraan SUV dengan hanya terdapat 4 penumpang salah satunya yakni pada Toyota Rush. Dimana pemilik memaksakan melakukan modifikasi Toyota Rush dari 4 penumpang menjadi 7 penumpang. Akan tetapi penambahan jumlah tempat duduk tersebut dapat menimbulkan ketidaknyamanan bagi penumpang kendaraan di bagian baris belakang. Oleh karena itu, artikel ini bertujuan untuk mendesain foot stand pada Toyota rush yang dimodifikasi menjadi 7 tempat duduk sehingga dapat meningkatkan kenyamanan penumpang. Proses desain dilakukan melalui tahap analisis konstruksi, desain, dan simulasi. Hasil menunjukkan bahwa penambahan foot stand dapat menambah kenyamanan bagi penumpang yang duduk di baris belakang karena memiliki ruang kaki yang lebih luas dan longgar.
\end{abstract}

Kata kunci: konsumen, foot stand (tempat kaki), ergonomis,dan kenyamanan, Whiplash Injury Lessening (WIL) Concept Seat.

\section{PENDAHULUAN}

Salah satu bidang otomotif memang pada zaman ini mengalami peningkatan,baik itu peningkatan fitur interior, eksterior, dll. Contohnya seperti mobil hemat energi, menggunakan fitur autonomus, dan fitur pendeteksi kemacetan yang merupakan perkembangan dari GPS. 
Seiring waktu berjalan, tingkat fitur digital semakin meningkat atau memuncak. Dengan demikian maka harus adanya pengimbangan antara kecanggihan fitur tersebut dengan tingkat ergonomis dan kenyamanan pada konsumen seperti, kenyamanan kabin untuk konsumen. Kenyamanan konsumen dalam artiannya saat konsumen menggunakan kendaraan tersebut tidak menyebabkan suatu cidera akibat fitur atau fasilitas yang terdapat di dalam atau di luar kendaraan. Kabin sendiri telah didisain dengan sedemikian rupa untuk meningkatkan tingkat ergonomisnya. Namun salah satu contohnya mobil produkan Toyota yaitu RUSH (2009) terdapat kekurangan yakni kabin yang sempit untuk bagian kaki penumpang pada sisi ruang kabin terutama di sektor penumpang belakang. Dengan disain ruang kabin di sektor belakang yang dibuat lega atau luas tersebut akan berdampak pada sektor penumpang paling belakang. Di mana, justru akan membuat ruang kaki penumpang belakang sempit. (semisena, 2020).

Pada masalah ini kenyamanan dari pengguna adalah yang paling utama, mengapa ? karena bilamana kenyamanan pengguna telah terenuhi maka secara otomatis akan meningkatkan jual beli kendaraan di pasaran, dengan melansirkan beberapa keunggulan dari kendaraan tersebut yang telah dilakukan penambahan fitur dan bukti nyata dari penggunanya. Dengan adanya penambahan fitur, yakni pada mobil Toyota RUSH (2009) untuk memberikan foot stand atau wadah kaki yang dengan tujuan agar kaki tidak selalu tertekuk dan leluasa untuk bergerak. Bilamana terdapat penambahan fitur ini diharapkan dapat memberikan kenyamanan konsumen atau pengguna. Bila kita bandingkan dengan Daihatsu terios yang memiliki kabin belakang yang cukup besar (stanly/otomania, 2020). Perbedaan 2 merk mobil tersebut dilansir pada showroommobil.co.id yang mengatakan bahwasanya mobil Daihatsu terios lebih unggul pada segi muatan penumpang dengan memiliki disain aslinya dapat mengangkut 7 penumpang dan apabila dibangkan dengan Toyota rush hanya semestinya memiliki batas muatan hingga 4 orang apabila terdapat kabin bagasi. Namun, kebanyakan orang selalu memaksakan memodif bagasi dengan menambahkan kursi penumpang, yang akan berdampak pada semakin kecilnya ruang untuk kaki penumpang. Dengan itu munculah fitur foot stand untuk kaki agar meminimalisir cidera yang diakibatkan karena semakin sempit kabin pada kaki penumpang.

\section{METODE}

Tujuan penelitian ini membuat berupa disain untuk melengkapi fitur yang telah mendukung kenyamanan dan keamanan dari mobil Toyota rush (2009). Penelitian ini diawali dengan melihat adanya tingkat ergonomis yang kurang bagi konsumen atau penumpang. Metode yang akan digunakan untuk mengatasi masalah ergonomis pada mobil produkan Toyota ini yaitu dengan menambahkan fitur untuk wadah kaki yang nyaman dan dibuat di bawah kabin penumpang pertama. Langkah berikutnya adalah studi literatur untuk mengetahui kondisi dan 
desain kabin mobil ( Bagus, A., Thedy Yogasara, \& EngS, 2020). Dengan menganalisis mulai dari ukuran kabin secara menyeluruh dari mobil Toyota rush sampai dengan mencari kriteria kabin ideal untuk mobil type SUV yang dimana ukuran yang mumpuni dan juga mengutamakan pengguna dengan tidak memaksakan merubah disain original mobil dari pabrikan. Seperti contoh Daihatsu terios, mobil tersebut dengan type yang hampir mirip dengan Toyota rush namun bedanya yakni terios memiliki disain original dengan kabin yang telah didisain mampu menampung 6-7 orang sesuai kursi yang ada.

Selanjutnya melakukan pendisainnan untuk membuat wadah kaki tersebut dengan menggunakan berbagai perlakuan sesuai dengan bahan yang akan diolahnya. Tatacara perancangan sebagai berikut :

1. Memahami konstruksi dari kabin Toyota RUSH tahun 2009

2. Mengukur dengan ukuran standar semacam celahan sebagai wadah kaki untuk meningkatkan nilai ergonomis dari penumpang atau konsumen tersebut. Dengan ukuran ke depan $15 \mathrm{~cm}$ dengan lebar 100-125 cm dan tinggi $40 \mathrm{~cm}$ keatas dan $5 \mathrm{~cm}$ kebawah.

3. Bahan yang digunakan untuk alasnya menggunakan karpet jenis $P V C$, mengapa demikian menggunakan bahan tersebut?. Karena keunggulanya yakni tidak mengakibatkan selip pada kaki dan tidak berbau yang menyengat dan perawatannya mudah (otomotif.kompas.com, 2020).

4. Untuk wadah kakinya sendiri didisain dengan bahan dasar dari karet yang kuat, agar dapat terlihat menyatu pada bagian kabinnya sendiri dan juga tingkat keamanan.

Selanjutnya melakukan pemotongan pada bagian kabin penumpang sesuai dengan ukuran yang tertera diatas dan juga melakukan penyetakan tempat atau wadah kaki dengan ukuran yang berbeda yakni dikurangi 5-10 mm dari setiap sisi. Bertujuan bahwa agar tepat atau wadah kaki tersebut dapat masuk ke bagian kabin yang telah diberikan rongga dan terdapat modifikasi dari ketinggian kursi pada kebin penumpang paling belakang dengan memberikan perbedaan ketinggin kurang lebih $5 \mathrm{~cm}$.

\section{HASIL DAN PEMBAHASAN}

Untuk pembahasan lebih lanjut yakni mengererti mengenai konstruksi bahan yang akan dilakukan modifikasi seperti jenis bahan, perlakuan yang perlu dilakukan untuk bahan agar tidak mengalami kerusakan. Hal ini merupakan hal yang terpenting karena juga agar menyangkut kerumitan atau tidaknya dengan meodif suatu komponen.

Kedua yakni memberiakan ukuran, pada metode tepatnya step yang kedua yakni pemberian ukuran yang sesuai dengan tidak terlalu lebar dan tidak juga terlalu sempit untuk kaki. Pada sub ini merupakan hal yang lebih diperhatikan, mengapa ? karena tiap-tiap orang memiliki ukuran 
96 Agit Sakti Nur Kholis

kaki yang berbeda, dengan itu mendisain dengan ukuran normalnya. Dengan itu konsumen agar mendapatkan nilai ergonomisnya.

Sedangkan bahan yang digunakan untuk sebagai alas untuk wadah kaki tersebut menggunakan jenis karpet $P V C$. Selain keunggulan yang dicantumkan pada step ke 3 tersebut, terdapat pula kelebihan menggunakan karpet $P V C$ yakni mengenai perawatannya yang mudah walaupun memiliki tekstur yang terlihat lebih tebal dan memiliki bentuk seperti mi keriting.

Pembentukan dari wadah kaki tersebut dengan bahan dasar yang terbuat dari karet yang kuat, mengapa? karena selain dapat menyamakan kontur kabin yakni menggunakan biaya yang lebih terjangkau dan cara cetak atau disain yang tidak terlalu rumit. Hasil yang didapatkan dari metode tersebut antaranya meningkatkan nilai ergonomis pada penumpang atau konsumen juga dapat menambahkan inovasi yang telah diciptakan oleh yokohama yakni Whiplash Injury Lessening (WIL) Concept Seat yang telah digunakan di mobil Toyota dengan tujuan meminimalisir cidera pada badan dan leher saat terjadi kecelakaan.

\section{Hasil}

Hasil analisa dari beberapa kabin mobil yang lebih besar maka juga pada tingkat kenyamanan juga menjamin, mengapa? karena pada mobil dengan kabin yang lebar maka terdapat tempat yang lega baik untuk kaki maupun tubuh dengan hal tersebut dapat meminimalisir adanya cidera pada tubuh akibat ruang gerak yang sempit. Contoh kabin mobi yang ideal dan nyaman dari type mobil yang sama dengan Toyota rus yakni type SUV adalah mobil pabrikan isuzu yakni merk isuzu MU-X pada mobi ini terdapat ukuran kabin yang jauh lebih lebar jika dibandingkan dengan rush. Dapat dilihat dari ukuran keseluruhan kabin yakni dengan panjang mobil $4845 \mathrm{~mm}$, Lebar $1860 \mathrm{~mm}$ dan Tinggi $1840 \mathrm{~mm}$ seta memiliki daya tampung 7 kursi yang didisain langsung dari (semisena, 2020).

Sedangkan dari model asli dari Toyota rush terdapatnya bagasi belakang yang mengakibatkan hanya terdapat 4 tempat duduk saja, dan apabila mengubah bagasi tersebut dengan menambah jumlah kursi maka tempat yang dibutuhkan seharusnya lebih agar tidak terlalu berhimpit yang mengakibatkan ketidaknyamanan pada penumpang. Terdapat beberapa komentar atas terlalu memaksakannya untuk menambahkan kursi pada bagasi Toyota rush. Dari kutipan Kobayogas.Com pada kabin paling belakang Toyota rush apabila dipaksakan dengan menambah bangku maka dampak yang diberikan saat orang dewasa duduk maka pada awalnya tidak terjadi keanehan namun untuk beberapa menit kedepan akan merasakan bahwa ketidak nyamanan akibat terlalu berhimpit pada bagian kaki yakni pada bagian lutut dan badan. 


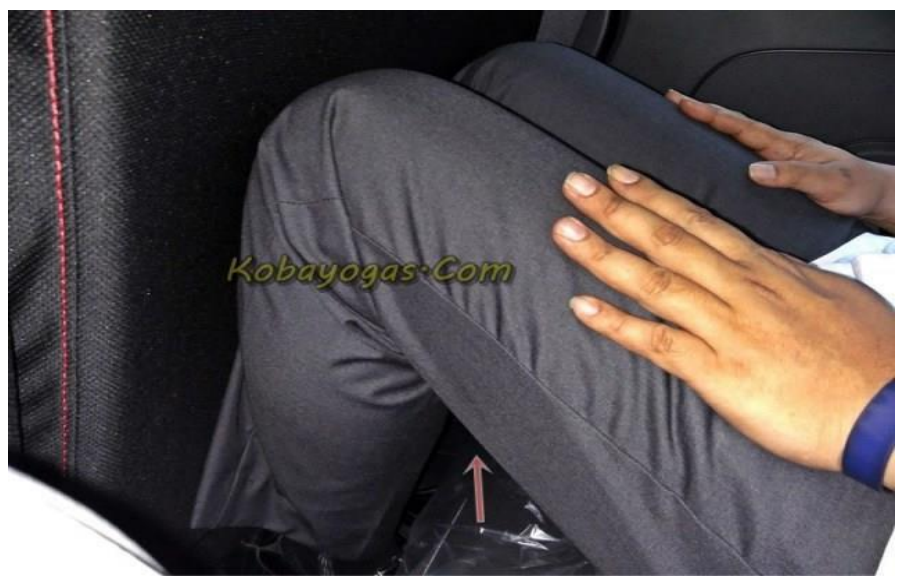

Gambar 1. Merupakan kondisi dimana pada saat Toyota rush 2009 melakukan penambahan bangku pada sector bagasi yang mengakibatkan gerak tubuh yang kurang leluasa saat duduk terlebih pada lutut.

Adapula beberapa dokumentasi mengenai modifikasi kabin mobi Toyota rush 2009 dengan menghilangkan bagasi dan menggantinya dengan kursi penumpang. Beserta lampiran tabel mengenai keunggulan dan kelemahan dari Toyota rush 2009.

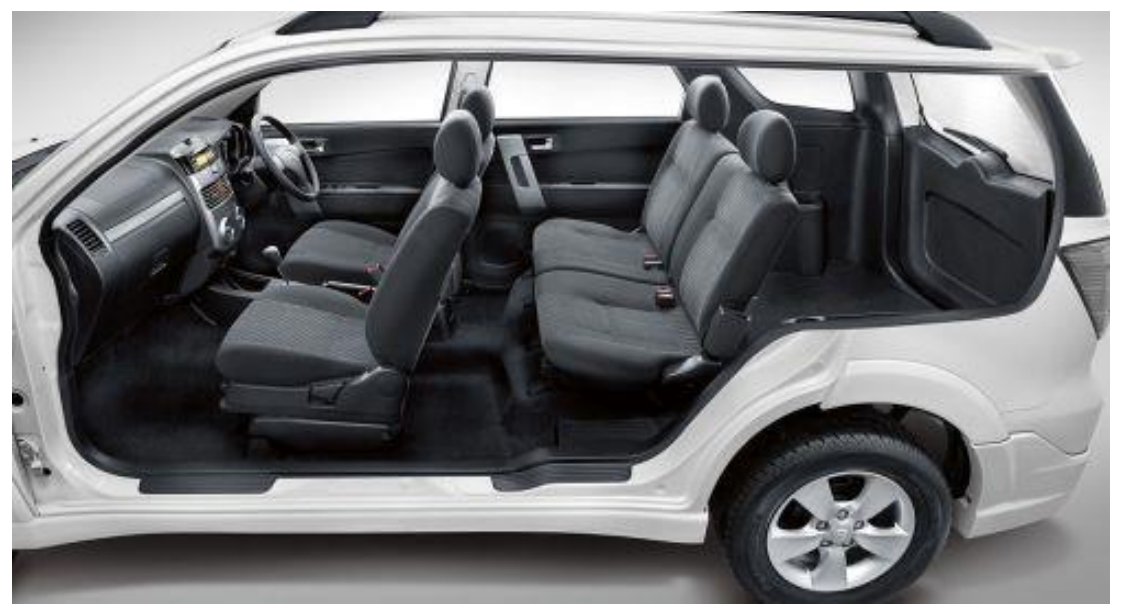

Gambar 2. Disan kabin Toyota rush 2009 yang memiliki bagasi, mampu mengangkut 4 orang dengan kursi tengah yang bergabung dan maksimal dapat mengangkut 5 penumpang termasuk sopir. 


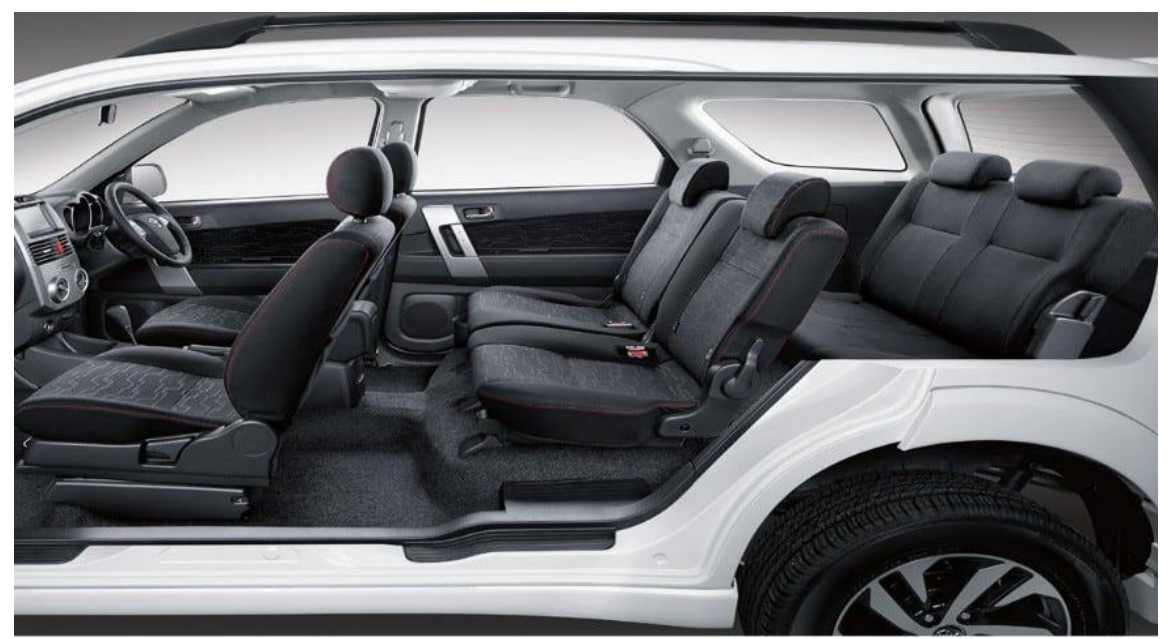

Gambar 3. Disain kabin Toyota rush 2009 yang telah dimodifikasi dengan tujuan dapat menampung 7 penumpang.

Tabel 1. Kelebihan dan kekurangan mobil Toyota Rush tahun 2009.

Kelebihan

Desain mobil yang begitu tangguh dan sporty

Perawatan mobil yang begitu mudah sparepart yang mudah dijangkau

Ruang kabik yang terlihat modern

Memiliki ruang bagasi yang luas
Kekurangan

Performa mesin tidaklak terlalu memumpuni

Suara mesin agak kasar, oleng

Fitur keselamatan dan keamanan masih kurang kabin

Hanya mampu menumpang 4-5

orang beserta bagasi dan

menampung 7 orang tanpa bagasi

Desain yang dibuat juga merupakan modifikasi antara kursi penumpang tambahan bagian belakang akan dibuat lebih pendek kurang lebih $5 \mathrm{~cm}$ dari kursi yang berada didepan, karena pada disain yang telah dibuat terdapat wadah kaki yang masuk ke sebagian kursi penumpang yang berada di depannya. Alas an tersebut juga dilandasi agar penumpang dapat menggerakka kakinya dengan lebih leluasa dan tidak berhimpit karena ruang yang terlalu sempit. Pada disain ini juga merupakan pelengkap dari Whiplash Injury Lessening (WIL) Concept Seat yang dapat meminimalisir cidera pada leher saat mengemudi lama. Dengan kombinasi antara Whiplash Injury Lessening (WIL) Concept Seat dengan foot stand maka kenyamanan pengguna akan terjamin. 


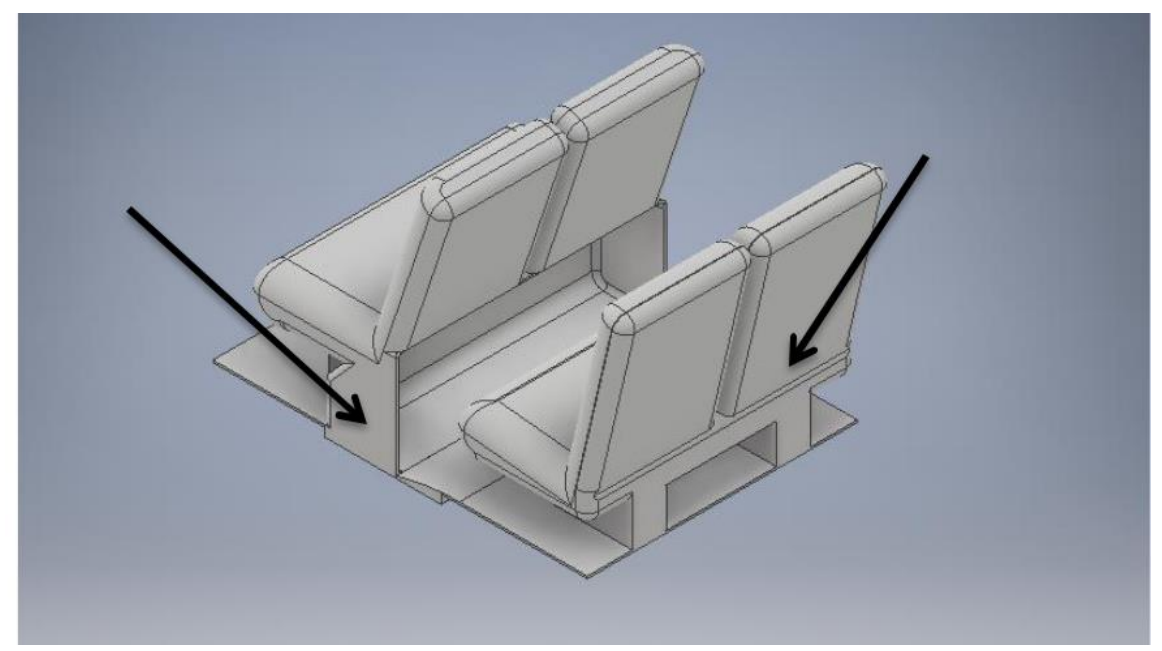

Gambar 4. Foot stand beserta simulasi tata letak kursi pada kabin

Letak foot stand terdapat pada bawah kursi ke dua dari kabin dengan sedikit memangkas atau memodif bagian kursi nomer 2 dengan memberi celah pada bagian belakang dan modifikasi ketinggian dari kursi paling belakang yang dibuat lebih rendah dari kursi nomor 2 .

\section{DISAIN}

(Skala 1:10)

Unit / Satuan : mm

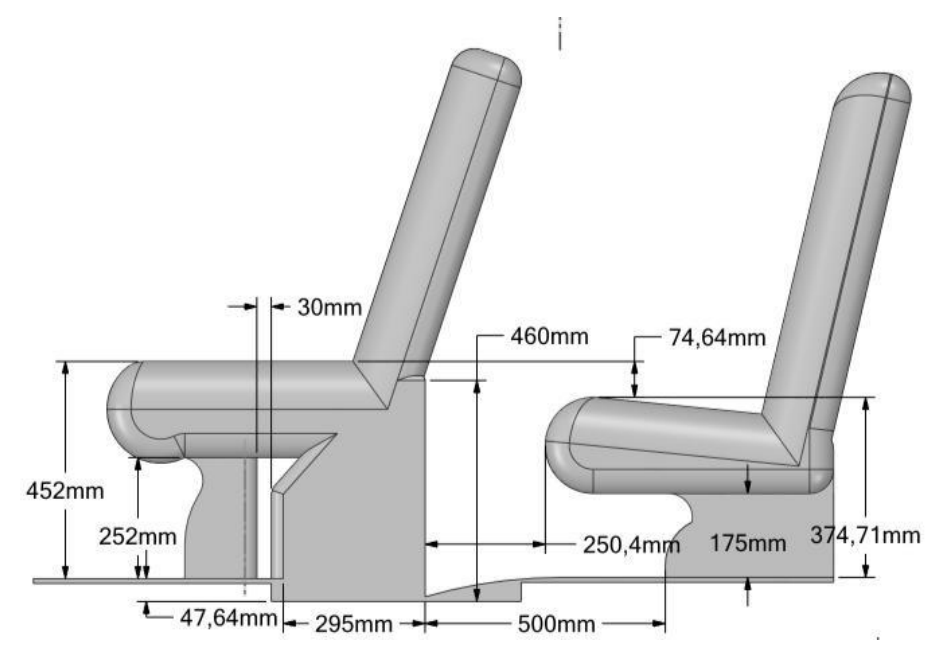

Gambar 5. Tampak samping ukuran foot stand beserta perkiraan jarak antar kursi 

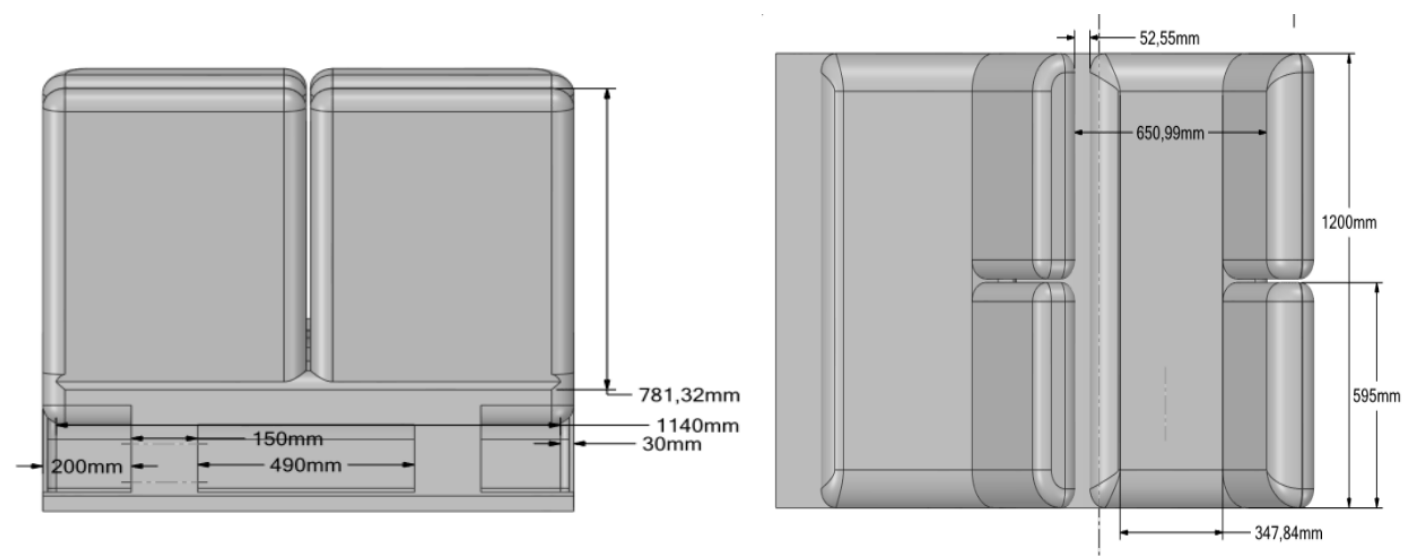

Gambar 6. Ukuran lebar pada foot stand serta lebar dan tinggi penopang kursi penumpang paling belakang dan tampak atas dari kursi kabin.

\section{Pembahasan}

Pada tabel mobil Toyota rush diatas menunjukan bahwa terdapat beberapa kekurangan salah satunya yang ingin ditekankan adalah kekurangan yakni " Fitur keselamatan dan keamanan masih kurang, serta kabin penumpang yang berhimpit “. Dengan itu sangat pentingnya membuat inovasi untuk kenyamanan bersama, salah satunya dengan menambahkan fitur foot stand, untuk meminimalisasi cidera pada kaki karena sesekali berhimpit pada kursi yang berada di depannya dan mendorong kelebihan pada mobil tersebut yakni ruang kabin tidak cukup luas untuk bagian kaki. Walaupun hanya akan berdampak sekitar 5-10 \% untuk meminimalisir pada bab keselamatan atau kenyamanan tersebut. Namun dapat diketahui juga bahwa lansirsan dari yokohama, kompasotomotif yakni sangat pentingnya keselamatan dan kenyamanan pengguna pada saat berkendara, pada lansiran tersebut yokohama membuat teknologi berupa Whiplash Injury Lessening (WIL) Concept Seat yaitu struktur jok yang dapat menyesuaikan lekuk tubuh atau terdapat perdam getaran pada bagian leher. Teknologi ini muncul karena berdasarkan survey dijepang bahwa sekitar 53\% cedera akibat kecelakaan berada pada bagian belakang.

Jepang juga menekankan hasil survey lain menunjukan bahwa 90\% cidera akibat kecelakaan tersebut pada bagian leher, sedangkan terdapat beberapa yang luput mengenai disain kabin yakni pada tingkat kenyamanannya. Sebagian kecil kemungkinan juga cidera yang diakibatkan oleh kecelakaan terdapat pada bagian kaki kebawah bukan hanya itu namun bilamana saat perjalanan jauh dan hal tersebut harus memaksakan kaki dengan posisi yang tidak mengenakkan atau secara ergonomis yang kurang savety, hal tersebut juga menjadi kunci dari cidera kaki.

Ruang kaki yang berhimpit pada kabin mobil tersebut dapat menyebabkan kaki tidur atau dapat disebut juga dengan kesemutan. Kaki tidur sendiri diakibatkan karena terdapat saraf yang tertindih atau tehimpit pada bagian lutut ataupu pergelangan kaki yang umumnya dikarenakan 
posisi kaki saat duduk yang terlalu menopang beban atau pada ruang yang sempit (convesia.com, 2020). Dari pernyataan tersebut dengan mengkombinasi teknologi dari yokohama yakni Whiplash Injury Lessening (WIL) Concept Seat dengan foot stand yang dianjurkan bagi mobil type SUV yang mendapati akan dilakukannya modifikasi dengan merombak bagasi belakang menjadi kabin penumpang agar dapat memuat penumpang yang lebih hingga 6-7 orang.

\section{SIMPULAN}

Kenyamanan dan keamanan konsumen ialah yang diprioritaskan. Kemungkinan penambahan fitur yang sederhana ini memberikan manfaat terlebih untuk meningkatkan nilai ergonomisnya. Dan juga menambahkan fitur pelengkap tersebut menjadikan suatu presentase akibat kecelakaan atau cidera akibat ruang gerak kaki yang terbatas dapat diminalisir dan sebagai pelengkap dari fitur Whiplash Injury Lessening (WIL) Concept Seat pada kabin penumpang.

\section{DAFTAR PUSTAKA}

Anonim. (2019). MU-X Mobil SUV yang berasal dari Negeri Samurai dengan kapasitas 7 orang yang nyaman dan aman digunakan di segala medan. Diakses pada 2019 dari https://www.semisena.com/mobil/isuzu-mu-x

Anonim. (2017). Kelebihan dan Kekurangan Toyota Rush. Diakses pada 2019 dari https://www.semisena.com/kelebihan-dan-kekurangan-toyota-rush.html

Apriliananda, Donny. (2017) . Keunggulan Karpet mie bahan PVC coil buat mobil. Diakses pada 2019 dari :

https://otomotif.kompas.com/read/2017/01/27/170100315/keunggulan.karpet.mie.baha n.pv\%20c.coil.buat.mobil.

Bagus, A., Eng, M., Thedy Yogasara, S. T., EngSc, M., Shirley Wulansatya.(2000). Evaluasi Dan Perancangan Ulang Ruang Kemudi Dan Penumpang Mobil Kancil Berdasarkan Prinsip Ergonomi. Jurnal. Bandung : Universitas Katolik Parahyangan.

Harvenda, Aris F. (2016). Ragam Pencegahan Cedera saat Kecelakaan di Mobil Toyota. Diakses pada 2019 dari :

https://lifestyle.kompas.com/read/2016/08/30/090200715/Ragam.Pencegah.Cedera.saa t.Kecelakaan.di.Mobil.Toyota?page $=$ all

Kobayogas. (2016). Impresi Duduk Di Belakang New Toyota Rush 7 .. Hanya untuk Anak Anak. Diakses pada 2019 dari http://kobayogas.com/2016/09/15/impresi-duduk-di-belakangnew-toyota-rush-7-hanya-untuk-anak-anak/

Sean, ila. (2019). 10 Gejala Aneh ini Sering Dialami Saat Berlari. Diakses pada 2019 dari https://covesia.com/lifestyle/baca/66982/10-gejala-aneh-ini-sering-dialami-saat-berlari

Suherman, Yogi. (2017). 15 Perbandingan Mobil Rush dan Terios Mana yang Lebih Baik?. Diakses pada 2019 dari https://showroommobil.co.id/info-mobil/perbandingan-mobilrush-dan-terios/

http://staffnew.uny.ac.id/upload/132243651/pendidikan/E2\%20Konsep\%20Das ar\%20Ergonomi.pdf 
102 Agit Sakti Nur Kholis 